\title{
The Effect of Social Support on Subjective Well-being: Mediator Roles of Self-esteem and Self-efficacy
}

\author{
$\mathrm{Xi} \mathrm{Xi}^{1, \mathrm{a}}$, Yu Wang ${ }^{1, \mathrm{~b},{ }^{*}}$ and Bin $\mathrm{Jia}^{1, \mathrm{c}}$ \\ ${ }^{1}$ Management School, Harbin University of Commerce, Harbin, Heilongjiang, P.R.China \\ acc_58@163.com, beudemonia_wy@163.com, ${ }^{\mathrm{c}} 13613667565 @ 163 . c o m$
}

Keywords: Social support, Subjective well-being, Self-esteem, Self-efficacy.

\begin{abstract}
Numerous studies have illustrated the relationship between social support and subjective well-being, the intermediary between this has not been examined detailedly. The article aims to explore the college students' subjective well-being on the background of cultural integration and social development, as well as the relationship between social support and subjective well-being: mediator roles of self-esteem and self-efficacy. The results indicated that: (1) Social support has positive effect on subjective well-being; (2) Self-esteem plays a partly intermediary role on the relationship between social support and subjective well-being; (3) Self-efficacy plays a partly intermediary role on the relationship between social support and subjective well-being.
\end{abstract}

\section{Introduction}

Diener defines Subjective well-b ${ }^{1}$ eing (SWB) as individual's cognitive evaluation and the positive or negative feelings of an individual, people's evaluations of their lives, it's a popular issue in the domain of positive psychology (Denier, 1984 ${ }^{[1]}$ ). SWB is the internal experience of respondent and measured by human's personal prospective (Denier, 1997 ${ }^{[46]}$ ). Subjective well-being is a meaningful construct, many studies have explored factors influence SWB, to name a few, income, religion, social support, gender and etc., individuals may show different features and degrees in different background and period (Ed Diener and Robert, 2002 ${ }^{[47]}$; Christopher G. Ellison, 1991 ${ }^{[29]}$ ). Since the concept of social support was first proposed to the literature, the discussion about the relationship between social support and SWB has largely been recognized (Sheldon Cohen and Cohen, S., \& Wills, $1985^{[12]}$ ).

Self-esteem tends to be a cognitive evaluation of the oneself, it refers to an individual's general sense of his or her value or worth (Rosenberg, $1979^{[7]}$ ). Present researches focus on social network, attachment, depressive system and the measurement invariance of self-esteem scale (Lee, 2016 ${ }^{[34]}$, Liu and Zhou, 2017 ${ }^{[35]}$, Han, 2017 ${ }^{[36]}$, Salerno, 2017 ${ }^{[37]}$, Chena and Zhang, 2017 $7^{[38]}$ ) without further research on the individual's emotion and improvement. Bandura's self-efficacy theory proposes that self-efficacy is a person's belief in their capacities to perform in certain ways that urge them to control over events and affect their lives, and self-efficacy indicates the amount of behavioral improvement (Bandura, 1977 ${ }^{[8]}$ ). It also has been proved that self-esteem has positive effect on the academic performance (Huong T. Bui, 2017 ${ }^{[39]}$ ).

SWB can be a soft metric to measure whether college students are growing healthily. The relationship between SWB and several variables such as hope and resilience has been proved in many studies (Bajaj, Pande, 2016 ${ }^{[44]}$; Seydi Ahmet, 2016 ${ }^{[45]}$ ), but the different measurement and samples lead to different results. Social support has strong positive effect on mental health (Cohen and Wills $1985^{[12]}$, we need to pay attention to the social resources a college student can receive. If a college student can get enough support from his parents and friends, he will be more confident and enthusiasm.

In this article, setting the Chinese college students for example, we firstly engage in discussing how social support influence SWB and try to prove whether the self-esteem and self-efficacy are the

\footnotetext{
${ }^{*}$ China Postdoctoral Science Foundation (2015M581466), HeiLongJiang Postdoctoral Science Foundation (LBHZ15111), Harbin University of Commerce Doctoral Foundation (14RW17).
} 
mediator between the relationship between social support and subjective well-being. The article contributes to the theoretical analysis about subjective well-being, connecting the subjective wellbeing with self-esteem, self-efficacy, social support and firstly study the relationship between the four variables, both discussing whether grade will have impact on subjective well-being. The article will come up with some suggestions of how to adjust the subjective well-being of college students to schools and social organizations. The hypothesises put forward in the article are built on existing literatures. We use questionnaire investigation to collect the data and construct a Structural Equation Model with Amos 23.0 to analyze the data.

\section{Hypothesis and Theoretical Model}

2.1 Social Support and Subjective Well-being Social support is defined as the perception or experience that one is loved and cared for, esteemed and valued, and part of a social network of mutual assistance and obligations (Wills $1991^{[4]}$ ). It's widely consensus that social support is closely related to SWB. (Baumeister and Leary, 1995 ${ }^{[5]}$; Karademas, 2006 ${ }^{[6]}$ ). Numerous studies have proved the positive relationship between social support and SWB, in which the control covariance is numerous (Diener, 2002 ${ }^{[9]}$; Gallagher, 2008 ${ }^{[10]}$ ). Social support encompasses a multitude of interactions between friends, families, classmates and other people (Sarason et al, $1987^{[11]}$ ). It's a very complex construct comprising various facets such as informative, instrumental, emotional social support (Cohen and Wills $1985^{[12]}$ ). Social support contributes to well-being by adding positive emotion and lowering the feeling of frustration and has a significantly positive correlation with life satisfaction and positive affect for this, but negative correlation with negative affect, it affects a range of life experience. It has been mentioned in the study that having close personal relationships with others contributed significantly to happiness (Diener and Seligman, 2002 ${ }^{[9]}$ ). School-related social support has positive on subjective well-being among teenagers have been proved, and the teacher's support is significant to the school satisfaction of students (Reddy, 2003 ${ }^{[52]}$; Tian a, 2015 ${ }^{[53]}$ ). The social network work and online communication can be regarded as social sources which is one kind of the social support, and there are studies to demonstrate that online behavior influences real-life behavioral, social capital also has been mentioned in social media studies, social media use has a positive effect on subjective well-being and social capital (Bumsoo, Yonghwan, 2017 ${ }^{[54]}$; Lonnqvist, Deters, $2016^{[55]}$ ). The involvement in a group or class also influences the college student's selfefficacy, self-esteem mediated the relationship between leadership strengths and life satisfaction is proved (Weber, Ruch, 2013 ${ }^{[56]}$ ). Hope fully mediated the impact of resilience on SWB, both the hope and resilience influenced by the social environment and experience (Satici, 2016 ${ }^{[31]}$ ). How social support contributes to well-being also has been discussed, social support is supposed to promote wellbeing by influencing self-confidence, emotions, and behaviors in a way that promotes positive affect (Cohenet al, 2000 ${ }^{[13]}$ ). As above all, we can make the following hypothesis:

H1: Social support has positive effect on subjective well-being

2.2 Social Support and Self-esteem Self-esteem is described as one's evaluation of self, while life satisfaction is evaluation of one's life (Rosenberg, $1979^{[7]}$ ). The same with social support, self-esteem has been shown to be a strong correlate of every component of SWB by many scholars, either college students or adult, high levels self-esteem represents the person do believe his value and worth, naturally, he would fell more happiness too (Chou, 1999 ${ }^{[32]}$; Diener \& Seligman, 2002 ${ }^{[9]}$; Kong, Zhao, $2013^{[33]}$. Some studies have demonstrated that social support exerts influence on well-being both directly and indirectly through certain cognitive mechanisms, personality factors etc. (Cohen and Wills $1985^{[14]}$; Karademas, 2006 ${ }^{[15]}$ ). Others consider that besides demographic characteristics, social relationship, personality, and self-esteem is one of the predictor variables of well-being, social support theoretically and empirically contribute to self-esteem while self-esteem contributes to SWB, selfesteem and life satisfaction are significantly related even though not as stronger as individualistic (Rosenberg, 1979 ${ }^{[7]}$; Bosson et al, 2000 ${ }^{[16]}$; Diener, 1995 $5^{[3]}$; Petra and Ronald, 2003 ${ }^{[17]}$, Zhang, Chen $\left(2016^{[57]}\right)$ indicated that Subjective well-being is mediated by children's support and self-esteem in 
older adults. The impact of in-group favoritism has been tested and the result shows the participants have positive effect on self-esteem by leading to believe their behavior (Iacoviello, 2017 ${ }^{[31]}$ ). A lot of studies prove that possessing power can lead to higher self-esteem, and power can also enhance SWB (Wang, 2015 ${ }^{[30]}$ ). Chena and Zhang $(2017)^{[38]}$ proved that perceived social support and self-esteem partially mediated the relationship between attachment and life satisfaction. Analogously, some studies set socialism as a mediator between self-esteem and SWB, hence social support contributes to get more self-esteem, and then enhance the level of well-being ( $\left.\mathrm{Li}, 2013^{[18]}\right)$. Individuals with strong religious faith usually report high-level well-being, because they are hopeful and confident effected by the religion (Christopher G. Ellison, 1991 ${ }^{[29]}$ ). So we make the following hypothesis:

H2: Social support has positive effect on self-esteem

H3: Self-esteem has positive effect on subjective well-being

2.3 Social Support and Self-efficacy Generally, social support contains internal part and exterior part, self-efficacy influence a person's confidence to reach his or her goals, obviously, operational support can strengthen a person, make he become more braver for dispensing with crises may happen in the future. Social support in a certain way is affected by families and friends (Kenneth and Mary E., 1983 ${ }^{[48]}$ ). Bandura (1997) pointed out that higher self-efficacy, better adaption to and better subjective well-being. Self-efficacy has likewise been shown to substantially relate to SWB (Adeyemo and Adeleye, 2008 ${ }^{[40]}$; Ahmed M, 2017 ${ }^{[41]}$ ), people who are confident to achieve what they want to have been proved to experience higher SWB than people that are not (Cohen, 2012 ${ }^{[19]}$; Strobel et al., 2011 ${ }^{[20]}$ ), and people's belief in their efficacy for engaging in social behaviors can causally contribute to subsequent self-perceptions and the evaluation of their lives, it seems self-efficacy and well-being is connected by satisfaction and achievability. Past studies showed that SWB had a meaningful relationship of shyness and self-efficacy, shyness and self-efficacy plays a mediator role between this in a sample of Chinese college students (Wang, 2013 ${ }^{[42]}$; Li, 2014 ${ }^{[50]}$ ). It should be mentioned that self-efficacy has been found to mediate the relationship between the characteristic or other sociological factors and SWB (Cohen, 2012 ${ }^{[19]}$; Strobel et al., 2011 ${ }^{[20]}$; Weber et al., 2013 ${ }^{[21]}$ ). Furthermore, there are studies proved the mediating effect of self-efficacy between subjective and other variables such as internet, attachment (Huang, 2006 ${ }^{[51]}$; Hampton, 2004 ${ }^{[52]}$ ). Studies have shown the direct influence of religious certainty on well-being (Christopher, 1991 ${ }^{[29]}$ ), and significant positive relationship between religiosity and self-efficacy has been proved (Watson, 1988 ${ }^{[43]}$ ). Above all, we can find the tight connection between social support, SWB and self-efficacy, So we make the following hypothesis:

H4: Social support has positive effect on self-efficacy

H5: Self-efficacy has positive effect on subjective well-being

From the above analysis, we propose a theoretical framework of the relationship among social support, SWB, self-esteem and self-efficacy (shown as Fig.1).

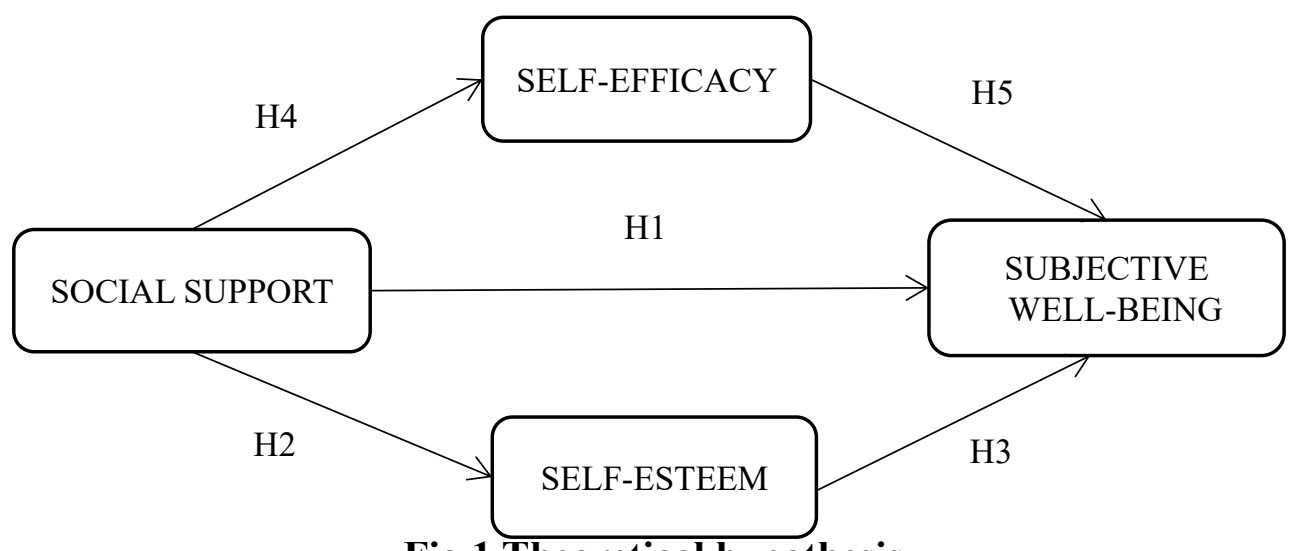

Fig.1 Theoretical hypothesis 


\section{Method}

3.1 Participants The research base in Chinese college students, the students from some universities or location may show similarity since they are live in the similar social environment. Aiming at obtaining diversity samples, which ensure the students from various majors, college and etc., we gave out questionnaires by network and about two weeks later, we got 370 questionnaires that remained 343 valid after processing, the effective rate reached $92.7 \%$. The descriptive statistics of from the samples are shown in Tab.1.

Tab.1 Descriptive statistics of formal the samples

\begin{tabular}{|c|c|c|c|c|c|c|c|}
\hline & & $\begin{array}{c}\text { Frequenc } \\
\mathrm{y}\end{array}$ & $\begin{array}{c}\text { Percentage( } \\
\%)\end{array}$ & & & $\begin{array}{c}\text { Frequenc } \\
\mathrm{y}\end{array}$ & $\begin{array}{c}\text { Percentage( } \\
\%)\end{array}$ \\
\hline \multirow[t]{2}{*}{$\begin{array}{l}\text { Gende } \\
\mathrm{r}\end{array}$} & Female & 206 & 40 & \multirow[t]{8}{*}{$\begin{array}{c}\text { College } \\
\text { Locatio } \\
n\end{array}$} & $\begin{array}{c}\text { Eastern } \\
\text { China }\end{array}$ & 39 & 11.37 \\
\hline & Male & 137 & 60 & & South China & 25 & 7.29 \\
\hline \multirow[t]{6}{*}{ Grade } & Freshman & 70 & 20.41 & & $\begin{array}{c}\text { Central } \\
\text { China }\end{array}$ & 32 & 9.33 \\
\hline & Sophomore & 62 & 18.08 & & North China & 48 & 13.99 \\
\hline & Junior & 140 & 40.82 & & $\begin{array}{c}\text { Northwest } \\
\text { China }\end{array}$ & 26 & 7.58 \\
\hline & Senior & 57 & 16.62 & & $\begin{array}{l}\text { Southwest } \\
\text { China }\end{array}$ & 14 & 4.08 \\
\hline & $\begin{array}{l}\text { Graduate } \\
\text { student }\end{array}$ & 4 & 1.16 & & $\begin{array}{l}\text { Northeast } \\
\text { China }\end{array}$ & 159 & 46.36 \\
\hline & $\begin{array}{c}\text { Doctoral } \\
\text { student }\end{array}$ & 10 & 2.91 & & & & \\
\hline \multirow[t]{8}{*}{ Major } & Economics & 66 & 19.24 & \multirow[t]{8}{*}{$\begin{array}{l}\text { College } \\
\text { Level }\end{array}$} & $211 \& 985$ & 27 & 7.87 \\
\hline & Pedagogy & 17 & 4.96 & & 211 & 94 & 27.41 \\
\hline & Literature & 19 & 5.54 & & $\begin{array}{c}\text { Non } 211 \text { or } \\
985\end{array}$ & 192 & 55.97 \\
\hline & Science & 16 & 4.66 & & $\begin{array}{l}\text { Junior } \\
\text { college }\end{array}$ & 30 & 8.75 \\
\hline & Engineering & 78 & 22.73 & & & & \\
\hline & Medicine & 19 & 5.54 & & & & \\
\hline & Management & 114 & 33.24 & & & & \\
\hline & Others & 14 & 4.09 & & & & \\
\hline
\end{tabular}

3.2 Variables and Measures We choose items of variables based on existing literatures which had been verified the validity and reliability when choosing the variables for investigating. And we adjusted the variables to fit the study. The Likert-type 4-point scale is taken to describe the variables in the questionnaire.

Under the unique social circumstance in China, Xiao has adjusted the questionnaire authorized by western scholars to fit it (Xiao, 1994 ${ }^{[22]}$ ), The social support rating scale (SSRS) designed by Xiao is divided into three aspects which contain 10 items. SSRS infer to subjective support, objective support and the availability of support, it evaluates a person' subjective well-being by judging the support from the families, friends, neighbors, classmates, and how to do the person takes advantages of the support. The Chinese scholars when referring to social support largely adopt SSRS and past studies proved the good validity and reliability of SSRS can reach the expectation (Liu, 2008 ${ }^{[23]}$ ).

Index of well-being contains the emotion assessment includes 8 items weight 1 and index of life satisfaction includes 1 items weight 1.1 is conducted by Campbell (Campbell, 1976 ${ }^{[24]}$ ). There are studies have pointed out that a significant gender difference was found on the index of well-being (Zhang, 2002 ${ }^{[49]}$ ) and also a significant correlation between an index of well-being and negative emotional. Index of well-being was negatively correlated with factor scores of emotional including state anxiety, trait anxiety, and SCI-90 depression, it is psychometrically sound for application to Chinese college students (Li, 2000 $\left.{ }^{[25]}\right)$. 
General Self-efficacy scale (GSES) adopted by Schwarzcr evaluates a person in one dimension and 10 items (Schwarzcr, 1997 ${ }^{[26]}$ ) is extensively used all over the world. We have to face the cultural difference between the western and eastern when using the scales. While the GSES is translated into Chinese, some items of GSES do not have a high discrimination and good test-retest reliability but the version of GSES has excellent internal consistency reliability and reliability, so we adjust the scale to fit the model $\left(\mathrm{Hu}, 2014^{[27]}\right)$.

Rosenberg Self-esteem Scale (RSES) is a very popular measuring instrument in many studies, but a problematic item is found in translation that cause low reliability, therefore, we adopt the suggestion raised by Shen, using a negative Chinese expression of the 8 th item (Shen, $2008^{[28]}$ ) to measure the self-esteem of college students.

\section{Results}

4.1 Confirmatory Factor Analysis As mentioned, the scales used in the questionnaire are based on existing scales which are tested the reliability and validity, some items of variables are changed in the questionnaire, to ensure the quality of scale, we do the first-order confirmatory factor analysis for measuring the items.

The testing results of social support (SS) are shown in the Fig.2, which contains the objective support, subjective support and the availability of support. The factor loadings of three items are 0.71 , 0.86 , and 0.69 , all above 0.5 and reach the expectation.

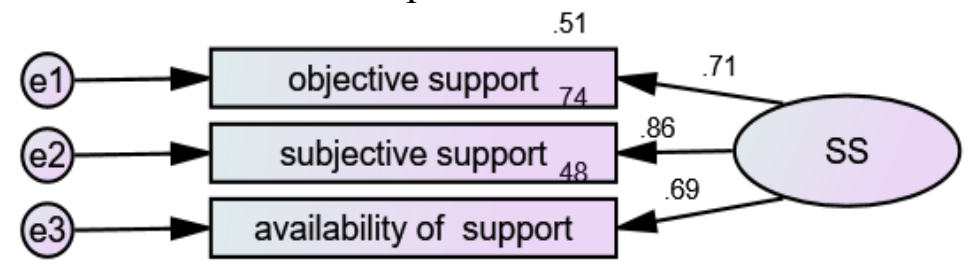

Fig.2 Confirmatory factor analysis results of social support

The testing results of subjective well-being (SWB) are shown in the Fig.3, the well-being scale has five dimensions to observe the latent variables, and the factor loadings of five items are $0.79,0.88$, $0.89,0.85,0.78$, all above 0.5 and reach the expectation.

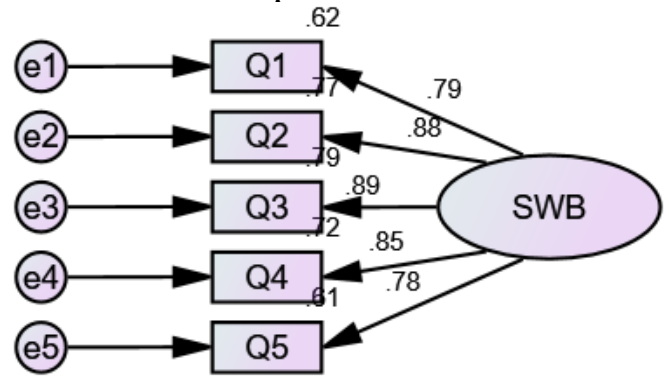

Fig.3 Confirmatory factor analysis results of subjective well-being

The testing results of Self-esteem (SEE) are shown in the Fig.4, the same with SWB, the scale have five dimensions to measure the SEE, The factor loadings of five items are $0.66,0.63,0.82,0.77$, and 0.66 , all above 0.5 and reach the expectation.

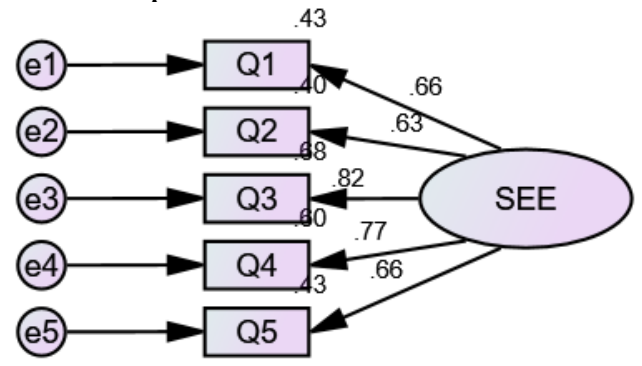

Fig.4 Confirmatory factor analysis results of self-esteem 
The testing results of Self-efficacy (SEF) are shown in the Fig.5, the same with SWB, the scale have five dimensions to measure the SEF, The factor loadings of five items are $0.77,0.69,0.70,0.72$, 0.70 , all above 0.5 and reach the expectation.

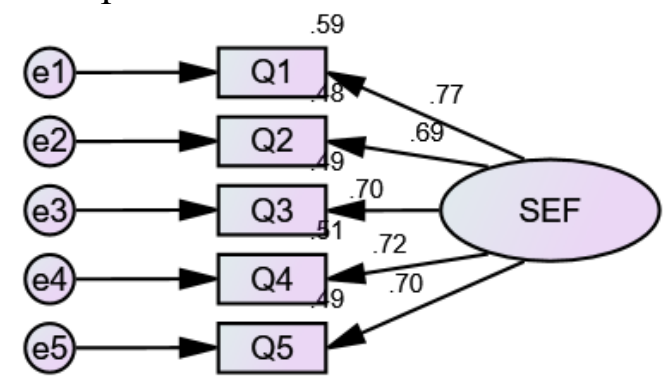

Fig.5 Confirmatory factor analysis results of self-efficacy

4.2 Reliability and Validity As for regional and traditional factors, though the scales we adapted are based on numerous studies and some scholars have examined the validity and reliability of the scale, we still need to test the reliability and validity of the scale to ensure the investigation targets we choose are fit the model we constructed. To avoid the malfunctioned results brought by incorrect measure model, Amos23.0 and SPSS24.0 were used to test the reliability and validity of scales and the results is shown in Tab.2. The CR of every construct is above 0.7 and the AVE is above 0.5. Cranach's $\alpha$ are all above 0.7 too. Thus, the results show decently good reliability and validity towards the scales used above.

Tab.2 Reliability and validity analysis

\begin{tabular}{cccc}
\hline Constructs & CR & AVE & Cranach's $\alpha$ \\
\hline SS & 0.800 & 0.573 & 0.748 \\
SWB & 0.922 & 0.704 & 0.921 \\
SEF & 0.840 & 0.513 & 0.834 \\
SEE & 0.836 & 0.506 & 0.840 \\
\hline
\end{tabular}

4.3Analysis Model We construct the structural equation modeling (SEM) shown in Fig. 6 to measure the mediator roles of self-efficacy and self-esteem between social support and subjective well-being, We first construct a direct model between SS and SWB to test the direct influence of SS on SWB (Model.1), and then we construct an indirect model to test the mediator influence of self-efficacy and self-esteem between SS and SWB(Model.2 is shown in Fig.6.

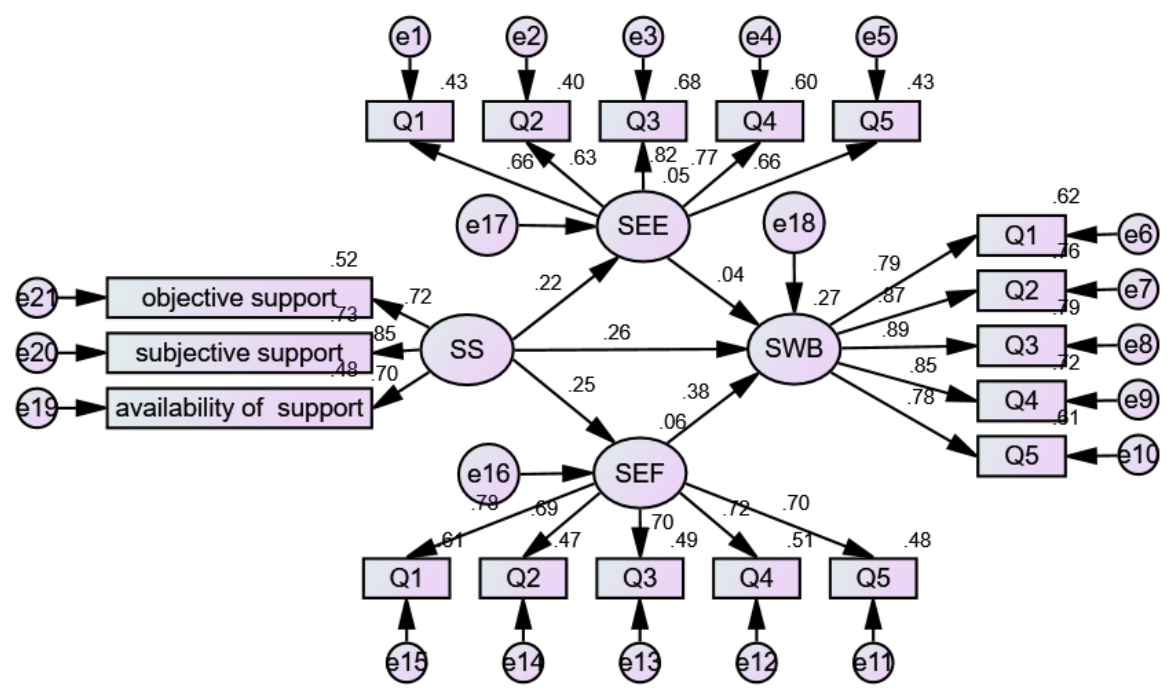

Fig.6 The analysis model.1

4.4 Model Fitness Amos 23.0 is used to verify the fit of the model, results shows that the data fit the model well, as we can see in the tab.3, normal fitness indexes are within the reference range except the AGFI while the AGFI is 0.891 and approximately to 0.9 , all in all, the model is suitable. 
Tab.3 Model fitness indexes

\begin{tabular}{ccc}
\hline Fitness indexes & Reference range & Model fitness \\
\hline CMN/DF & $<3$ & 2.311 \\
GFI & $>0.9$ & 0.917 \\
AGFI & $>0.9$ & 0.891 \\
RMSEA & $<0.08$ & 0.062 \\
TLI & $>0.9$ & 0.934 \\
IFI & $>0.9$ & 0.944 \\
CFI & $>0.9$ & 0.944 \\
\hline
\end{tabular}

4.5 Paths Analysis Four paths hypotheses are verified from the path analysis results shown in Tab.4, social support to self-efficacy, social support to self-esteem, and self-esteem to subjective well-being, as well as social support to subjective well-being, is significant under 0.01, among which self-efficacy to subjective well-being is significant above 0.5 , for which the path coefficients are $0.083,0.119$, $0.110,0.754$ and 0.250 separately. Thus, the hypothesis $1,2,3$, and 4 is all supported by empirical tests. To further measure the mediator influence of self-efficacy between social support and subjective well-being, we construct another model.3 to test it single. The model is shown in Fig.7.

Tab.4 Verified results of each model

\begin{tabular}{ccccc}
\hline & Estimates & S.E & C.R & P \\
\hline SEF $<---S S$ & 0.083 & 0.025 & 3.341 & $* * *$ \\
SEE<---SS & 0.119 & 0.033 & 3.652 & $* * *$ \\
SWB $<---S E F$ & 0.110 & 0.165 & 0.68 & 0.504 \\
SWB $<---S E E$ & 0.754 & 0.138 & 5.457 & $* * *$ \\
SWB $<---S S$ & 0.250 & 0.059 & 4.242 & $* * *$ \\
\hline
\end{tabular}

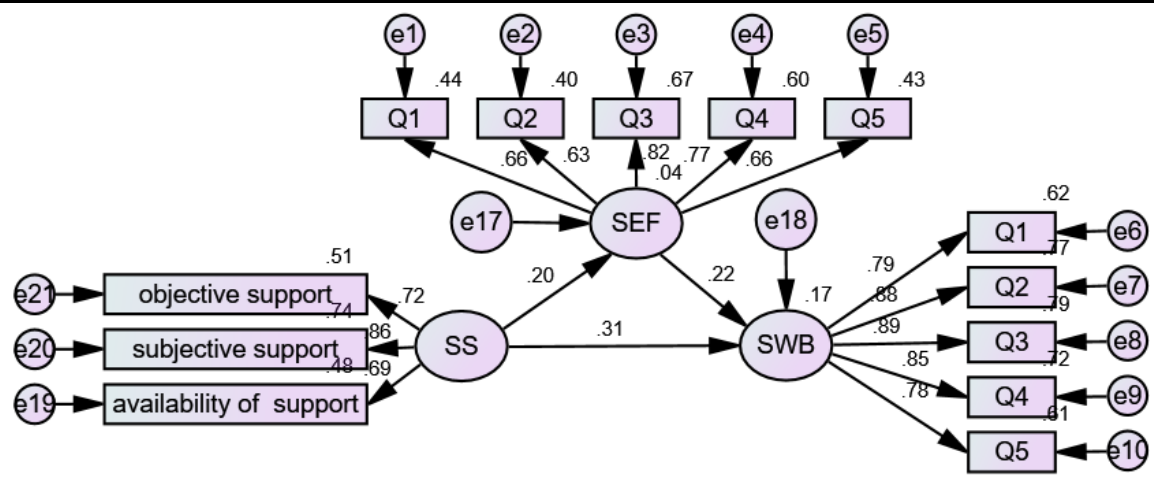

Fig.7 The analysis model.2

As the results of model.3 shown in Tab.5, three paths hypotheses are verified, among which social support to self-efficacy is significantly under 0.005 , self-efficacy to subjective well-being, social support to subjective well-being is significant under 0.001 . Thus, the hypothesis 1,4 , and 5 is supported by empirical tests.

Tab.5 Verified results of each model

\begin{tabular}{|c|c|c|c|c|}
\hline & Estimates & S.E & C.R & $\mathrm{P}$ \\
\hline $\mathrm{SEF} \leftarrow \mathrm{SS}$ & 0.074 & 0.024 & 3.014 & 0.003 \\
\hline $\mathrm{SWB} \leftarrow \mathrm{SEF}$ & 0.592 & 0.160 & 3.704 & $* * *$ \\
\hline $\mathrm{SWB} \leftarrow \mathrm{SS}$ & 0.297 & 0.061 & 4.839 & $* * *$ \\
\hline
\end{tabular}

4.6 Mediating Role Test As shown in Tab.6, the results of the mediating role testing show either total effect, direct effect and indirect effect in the path of "SS $\rightarrow$ SWB" are above 1.96. And zero is not contained in the confidence interval neither of Bias-Corrected or Percentile which means that both direct and indirect effects exist and are significant. Hence, the hypothesis put forward in the article is proved that self-efficacy and self-esteem are partly mediating variables between social support and subjective well-being. 
Tab.6 Result of mediating role test

\begin{tabular}{|c|c|c|c|c|c|c|c|}
\hline \multirow{3}{*}{ Paths } & \multirow{3}{*}{$\begin{array}{c}\text { Point } \\
\text { Estimates }\end{array}$} & \multirow{2}{*}{\multicolumn{2}{|c|}{$\begin{array}{c}\text { Product of } \\
\text { Coefficients }\end{array}$}} & \multicolumn{4}{|c|}{ Bootstrapping } \\
\hline & & & & \multicolumn{2}{|c|}{ Bias-Corrected 95\% CI } & \multicolumn{2}{|c|}{ Percentile $95 \%$ CI } \\
\hline & & $\mathrm{SE}$ & Z & Lower & Upper & Lower & Upper \\
\hline \multicolumn{8}{|c|}{ Total Effect } \\
\hline $\mathrm{SS} \rightarrow \mathrm{SWB}$ & 0.349 & 0.065 & 5.370 & 0.231 & 0.484 & 0.223 & 0.479 \\
\hline \multicolumn{8}{|c|}{ Direct Effect } \\
\hline $\mathrm{SS} \rightarrow \mathrm{SWB}$ & 0.250 & 0.063 & 3.969 & 0.136 & 0.382 & 0.126 & 0.377 \\
\hline \multicolumn{8}{|c|}{ Indirect Effect } \\
\hline $\mathrm{SS} \rightarrow \mathrm{SWB}$ & 0.099 & 0.035 & 2.829 & 0.040 & 0.177 & 0.039 & 0.175 \\
\hline
\end{tabular}

4.7 Empirical Results Analysis For further exploring whether the result changed if gender, grade and school level are controlled. SPSS 24.0 was used to do independent samples T test. The results show that for female and male, there is no difference in social support, self-efficacy, SWB while male have higher self-esteem level than female (sig. (2-tailed) is 0.001). The senior has higher self-esteem level than freshman and sophomore, (sig. (2-tailed) is 0.004, sig. (2-tailed) is 0.001) and higher selfefficacy level than sophomore (sig. (2-tailed) is 0.025), then there are no different in the other facets for the college students in different grade. The level of school is not a factor contributes to college student's self-esteem, self-efficacy and the level of social support and SWB.

(1) Social support has a positive effect on subjective well-being. That means the SWB is effected by the support by families, friends and the availability of support, for families can only try to pay more attention on children or relatives who are a college students, in this way, the college students will feel more confident and, high level SWB can reduce the possibility of suicide and depression. For Chinese college student, the time they need to make decisions are knocking at the door, some of them may take part in the postgraduate entrance exams, civil servants or public institution examinations, and others will exert his or her heart and strength to get a job then become a member of employment under much pressure, high level social support can urge the students have a better realization about this period and do the as perfectly as choices they can.

(2) Social support has an indirect effect on subjective well-being via self-esteem and self-efficacy, which means self-efficacy and self-esteem plays mediator roles in the relationship between social support and subjective well-being. The results indicate that we can improve the level of SWB by improving the level of self-efficacy and self-esteem, in other words, college students with high levels of social support are likely to engage in better self-efficacy and self-esteem, which in turn contributed to the evaluations of life and positive affect while lower negative affect.

\subsection{Discussion}

The study presents that self-efficacy and self-esteem take part in the effect of social support on subjective well-being as mediator roles, and the finding is consistent with the previous results of $\mathrm{Li}$, Shi and Dang, 2014[50], Rosenberg, 1979[7], Diener and Diener, 1995[3]). In fact, the article indicates that social resource truly contributes to the college students to be more confident and enthusiastic to solve the problem, have the courage of facing the music, achieve the goals bravely since there are someone support them (Karademas, E. C, 2006[15]; Gallagher, 2008[10], Karademas, E. C, 2006[6]). The relationship between self-esteem and SWB is coincident with Kong, F., Zhao, J., $\&$ You, X (2013), and the deeper the college student involved in the group or class, the students will show higher optimism (Iacoviello, Berent, 2017[31]), the social stages offer college students opportunities to show themselves. Self-efficacy influences the academic performance and achievement of college students, the human spirit of transcending oneself urge the college students to evaluate himself by the accomplishment they have been achieved, in other words, it's the selfefficacy have impact on the self-assessment (Bandura, 1977[8]; Ahmed M, 2017[41]).

The result shows male has a higher self-esteem level than female and male show more confident about character. Hence in a Chinese university, the senior will be the first teacher for the freshman, 
senior can get more respect and support in some way so the senior naturally has a higher self-esteem level than freshman and sophomore. Another result of this study is to show that self-efficacy and selfesteem moderated the significantly influence of the subjective social support on SWB than the other components of social support like objective support and availability of support, the Chinese students who reported a high level subjective social support will have higher scores in SWB while there is no difference in objective support and availability. This finding may be explained by the value change in college students and the cultural difference between china and other countries.

\section{Conclusions}

5.1 The Present Findings By path analysis, we intended to examine the impacting mechanisms of social support on subjective well-being through self-esteem and self-efficacy in a sample of Chinese college students. As we anticipated, analysis results proved that every component of SWB have a significant relationship with social support. Each component of self-esteem and self-efficacy has similar influence on SWB while subjective support influence SWB most as a component of social support. These results in agreement with early studies that reported the relationships between SWB and social support (Diener and Seligman, 2002 ${ }^{[9]}$; Gallagher and Vella-Brodrick, 2008 ${ }^{[10]}$; Chen et al. 2006), SWB and self-esteem (Chen et al. 2006; Rosenberg, 1979 ${ }^{[7]}$; Bosson et al, 2000 ${ }^{[16]}$; Petra and Ronald, $\left.2003^{[17]}\right)$. In this study, we find out that self-efficacy and self-esteem acted as mediators of the relationship between social support and SWB, in other words, the previously reported mediating role of self-esteem and self-efficacy is robust with a different cultural samples.

Recently studies refer to SWB are around internal conditions such as religion, resilience, gender (Bajaj, Pande, 2016 ${ }^{[44]}$; Christopher G. Ellison, 1991 ${ }^{[29]}$ ), few studies focus on the relationship between the four variables studied in the article while it is meaningful to measure the college student's self-esteem and self-efficacy and find out whether the relationship with SWB is changed with the social change and culture integrated. Different with the previous studies, the present studies simultaneous adopt the self-efficacy and self-esteem as mediators to explain the effect mechanism of social support on SWB, it further elucidates the relationship between the two variables. This article is necessary to demonstrate that self-esteem and self-efficacy partly mediated the impact of social support on the emotion and the satisfaction of life, it's distinguishing with earlier study result conducted by Feng Kong (2013). This indicates that an assessment on SWB from emotional factor and the satisfaction of life. For each component may influence and show a different result.

Present study also offers an empirical framework for the researchers through testing self-efficacy and self-esteem as mediators between social support and SWB in a sample of Chinese college students. The description of current SWB, social support, self-esteem, self-efficacy levels differ in gender and grade not only verified the previous results shown by Zhang and Leung $\left(2002^{[49]}\right)$ and put up forward a new phenomenon that the senior naturally has a higher self-esteem level than freshman and sophomore. Also, the study may provide valuable guidance of how to implement psychological interventions designed to improve well-being.

5.2 The Practical Implication The result shows that we can state self-esteem and self-efficacy as a motivational effective system which functions to adjust a college student's social environment for signs of rejection and acceptance. Both, the result proves that low self-esteem and self-efficacy are caused by experiences of social rejection and criticism, which lead to the college student sensitive to negative social evaluations. For parents and schools, according to our study, parents and schools are supposed to pay more attention on the self-efficacy and self-esteem of a college student to have a profound influence on the interplay between social support and SWB. For college students, if the college students desire to improve the academic performance and learning efficiency, excepting selfcontrol and self-motivation, to take advantage of the support given by friends and families is another efficient way.

5.3 Limitations and Future Studies Further researches on this topic are suggested to making 
improvements for the following aspects: (1) We do not analysis the relationship between self-efficacy and self-esteem nor seriously measure which has a stronger effect as a mediator role, it's certainly a new research worth to study; (2) We adapted the scale conducted by Campbell to test the SWB, it refers to two dimensions contains emotion and satisfaction of life but do not distinguish the positive emotion and negative emotion, it is certainly a new research to measure whether self-esteem and selfefficacy have different influence on positive emotion and negative emotion; (3) The data we selected cannot reflect the college major and school location weather factors that have impact on college students' self-esteem, self-efficacy, and the level of social support and SWB; (4) The results indicate that self-efficacy and self-esteem are partially mediators, in addition to this, some external factors may also mediate the effect of social support on SWB, this is clearly an area for us to further exploration.

\section{References}

[1] Diener E, Subjective Well- Being, Psychology Bulletin, vol.95, pp. 542-575, 1984.

[2] Rosenberg, F, Global self-esteem and specific. self-esteem: Different concepts different outcomes, American Sociological Review, vol.60, pp. 141-158, 1995.

[3] Diener E, Diener M, Crosscultural correlates of life satisfaction and self-esteem, Journal of Personality and Social Psychology, vol.68, pp. 653-663, 1995.

[4] Wills, T. A, Social support and interpersonal relationships, Prosocial behavior. Newbury Park, pp. 265-289, 1991.

[5] Baumeister, R., \& Leary, M, The need to belong: Desire for interpersonal attachments as a fundamental human motivation, Psychological Bulletin, vol.177, pp. 497-529, 1995.

[6] Karademas, E. C., Self-efficacy, social support and well-being: The mediating role of optimism, Personality and Individual Differences, vol.40, pp. 1283-1290, 2006.

[7] Rosenberg, M, Conceiving the self, New York: Basic Books, 1979.

[8] Bandura, A. Self-efficacy: toward a unifying theory of behaviour change, Psychological Review, vol.1, pp. 199-215, 1977.

[9] Diener, E. \& Seligman, E. Very happy people, Psychological Science, vol.13, pp. 82-84, 2002.

[10] Gallagher, E. N., \& Vella-Brodrick, D. A., Social support and emotional intelligence as predictors of subjective well-being, Personality and Individual Differences, vol.44, pp. 1551-1561, 2008.

[11] Sarason, I. G., Sarason, B. R., Shearin, E. N., \& Pierce, G. R., A brief measure of social support: Practical and theoretical implications, Journal of Social and Personal Relationships, vol.4, pp. 497-510,1987.

[12] Sheldon Cohen, Cohen, S., \& Wills, T. A, Stress, social support and the buffering hypothesis, Psychological Bulletin, vol.98, pp. 310-357, 1985.

[13] In S. Cohen, L.Underwood, \& B. Gottlieb (Eds.), Social support measurement and intervention: A guide for health and social scientists, New York: Oxford University Press, vol.52, pp. 3-28, 2000.

[14] Cohen, S., \& Wills,T. A. Stress, social support and the buffering hypothesis, Psychological Bulletin, vol.98, pp. 310-357, 1985.

[15] Karademas, E. C. Self-efficacy, social support and well-being: The mediating role of optimism, Personality and Individual Differences, vol.40, pp. 1281-1290, 2006. 
[16] Bosson, J. K., Swann, W. B., \& Pennebaker, J. W., Stalking the perfect measure of implicit selfesteem: The blind men and the elephant revisited?, Journal of Personality and Social Psychology, vol.79, pp. 631-643, 2000.

[17] Petra, S., \& Ronald, F., The influence of social support and problematic support on optimism and depression in chronic illness: A prospective study evaluating self-esteem as a mediator, Health Psychology, vol.22, pp. 123-129, 2003.

[18] Li Ling. \& Liu Ya, The Relationship between Self-esteem and Well-being of Undergraduates: The Mediating Effect of Social Support, China Journal of Health Psychology, pp. 627-629, 2013.

[19] Cohen, K., \& Cairns, D., Is searching for meaning in life associated with reduced subjective well-being? Confirmation and possible moderators, Journal of Happiness Studies, vol.13, pp. 313-331, 2012.

[20] Strobel, M., Tumasjan, A., \& Spo“rrle, M., Be yourself, believe in yourself, and be happy: selfefficacy as a mediator between personality factors and subjective well-being, Scandinavian Journal of Psychology, vol.52, pp. 43-48, 2011.

[21] Weber, M., Ruch, W., Littman-Ovadia, H.,Lavy, S., \& Gai, O, Relationships among higher-order strengths factors, subjective well-being, and general self-efficacy-the case of Israeli adolescents, Personality and Individual Differences, vol.55, pp. 322-327, 2013.

[22] Xiao ShuiYuan, The theoretical and application of general social support scale, Journal of Clinical Psychiatry, pp. 98-100, 1994.

[23] Liu Ji Wen, Li Fu Ye, Lian Yu Long, Investigation of reliability and validity of the social support scale, Journal of XinJiang medical university, pp. 1:3, 2008.

[24] Campbell A, Converse PE, Rodgers WL, The Quality of American Life, New York: Russell Sage Foundation, vol.2, pp. 694-696, 1976.

[25] Li Jing, Zhao YuJin, Validation of index of well-being in a sample of Chinese college students, Chinese Journal of Clinical Psychology, pp. 225-226, 2000.

[26] Schwarzcr, R., \& Aristi, B, Optimistic self-beliefs: Assessment of general perceived self-efficacy in thirteen culture, World Psychology, pp. 177-190, 1997.

[27] Hu XiangLing, Tian ChunFeng, Sun FangJin. Reliability and Validity of the Chinese Version of General Self-efficacy Scale, Psychological Exploration, pp. 53-56, 2014.

[28] Shen ZiLi, Cai TaiSheng. Disposal of The 8th Item of Rosenberg Self-efficacy Scale in Chinese Version, Chinese mental health journal, pp. 661-663, 2008.

[29] Christopher G.Ellson, Religious Involvement and Subjective Well-Being, Journal of Health and Social Behavior, vol.32, pp. 80-89, 1991.

[30] Yi Nan Wang. Two mediators of power on subjective well-being in China, Personality and Individual Differences, vol.77, pp. 22-24, 2015.

[31] Vincenzo Iacoviello, Jacques Berent, Natasha Stine Frederic, Andrea Pereira. The impact of ingroup favoritism on self-esteem: A normative perspective, Journal of Experimental Social Psychology, vol.71, pp. 31-35, 2017.

[32] Chou, K. -L, Social support and subjective well-being among Hong Kong Chinese young adults. The Journal of Genetic Psychology, vol.160, pp. 319-320, 1999.

[33] Kong, F., Zhao, J., \& You, X, Self-esteem as mediator and moderator of the relationship between social support and subjective well-being among Chinese university students, Social Indicators 
Research, vol.112, pp. 151-159, 2013.

[34] Tae-Hoon Lee, Tae Hyun Kim, Woorim Kim, Eun-Cheol Park, Effects of difference in selfesteem between spouses on depressive symptom: Result from a data nationally representative of South Korean, Psychiatry Research, pp. 623, 2016.

[35] Qing-Qi Liu, Zong-Kui Zhou, Xiu-Juan Yang, Geng-Feng Niu, Yuan Tian, Cui-Ying Fan, Upward social comparison on social network sites and depressive symptoms: A moderated mediation model of self-esteem and optimism, Personality and Individual Differences, vol.135, pp. 223-225, 2017.

[36] Suejung Han, Attachment insecurity and openness to diversity: The roles of self-esteem and trust, Personality and Individual Differences, vol.111, pp. 291-293, 2017.

[37] Laura Salerno, Sonia Ingoglia, Gianluca Lo Coco, Competing factor structures of the Rosenberg Self-Esteem Scale (RSES) and its measurement invariance across clinical and non-clinical samples, Personality and Individual Differences, vol.113, pp. 13-14, 2017.

[38] Wanfen Chen, Dajun Zhang, Yangu Pan, Tianqiang Hu, Guangzeng Liu, Shilan Luo, Perceived social support and self-esteem as mediators of the relationship between parental attachment and life satisfaction among Chinese adolescents, Personality and Individual Differences, vol.108, pp. 98-100, 2017.

[39] Huong T. Bui, Kevin Kam Fung So, Anna Kwek, John Rynne, The impacts of self-efficacy on academic performance: An investigation of domestic and international undergraduate students in hospitality and tourism, Journal of Hospitality, Leisure, Sport \& Tourism Education, vol.20, pp. 47-50, 2017.

[40] Adeyemo, D. A., \& Adeleye, A. T., Emotional intelligence, religiosity, and self-efficacy as predictors of psychological well-being among secondary school adolescents in Ogbomoso, Europe's Journal of Psychology, vol.4, pp. 51 - 55, 2008.

[41] Ahmed M. Abdel-Khalek, David Lester, The association between religiosity, generalized selfefficacy, mental health, and happiness in Arab college students, Personality and Individual Differences, vol.109, pp. 12-16, 2017.

[42] Junni Wang, Jingjing Zhao, Yonghui Wang, Self-efficacy Mediates the Association Between Shyness and Subjective Well-Being: The Case of Chinese College Students, Social Indicators Research, vol.119, pp. 341-351, 2013.

[43] Watson, P., Morris, R., \& Hood, R, Sin and self-functioning: II. Grace, guilt, and psychological adjustment, Journal of Psychology \& Theology, vol.16, pp. 270-273, 1988.

[44] Badri Bajaj, Neerja Pande, Mediating role of resilience in the impact of mindfulness on life satisfaction and affect as indices of subjective well-being, Personality and Individual Differences, vol.93, pp. 63-67, 2016.

[45] Seydi Ahmet Satici, Psychological vulnerability, resilience, and subjective well-being: The mediating role of hope, Personality and Individual Differences, vol.102, pp. 68-73, 2016.

[46] Ed Diener, Eunkook Suh, anal Shigehiro Oishi, Recent Findings on Subjective Well-being, Indian Journcal of Clinical Psychology, vol.24, pp. 1-24, 1997.

[47] Ed Diener and Robert Biswas-Diener, Will money increase subjective well-being?, Social Indicators Research, vol.57, pp. 119-127, 2002.

[48] Kenneth Heller, Mary E. Procidano, Measures of Perceived Social Support From Friends and From Family: Three Validation Studies, American Journal of Community Psychology, vol.11, 
pp. 1-3, 1983.

[49] Zhang, L., \& Leung, J, Moderating effects of gender and age on the relationship between selfesteem and life satisfaction in mainland Chinese, International Journal of Psychology, pp. 8391, 2002.

[50] Caina Li, Xinxin Shi, Jianning Dang, Online communication and subjective well-being in Chinese college students: The mediating role of shyness and social self-efficacy, Computers in Human Behavior, vol.34, pp. 89-95, 2014.

[51] Huang, Z., Qian, M. Y., \& Yi, C. L, Correlated factors comparison: the trends of computer game addiction and internet relationship addition, Chinese Journal of Clinical Psychology, vol.14, pp. 244-247, 2006.

[52] Reddy, R., Rhodes, J. E., \& Mulhall, P, The influence of teacher support on student adjustment in the middle school years: a latent growth curve study, Development and Psychopathology, vol.15, pp. 119-126, 2003.

[53] Lili Tian a, Jie Zhao a, b, E. Scott Huebner, School-related social support and subjective wellbeing in school among adolescents: The role of self-system factors, Journal of Adolescence, vol.45, pp. 138-142, 2015.

[54] Bumsoo Kim a, Yonghwan Kim. College students' social media use and communication network heterogeneity: Implications for social capital and subjective well-being, Computers in Human Behavior, pp. 620-628, 2017.

[55] Jan-Erik Lonnqvist, Fenne große Deters b. Facebook friends, subjective well-being, social support, and personality, Computers in Human Behavior, vol.55, pp. 113-120, 2016.

[56] Marco Weber, Willibald Ruch, Hadassah Littman-Ovadia, Shiri Lavy, OrGai, Relationships among higher-order strengths factors, subjective well-being, and general self-efficacy-The case of Israeli adolescents, Personality and Individual Differences, vol.55, pp. 322-327, 2013.

[57] Xing Zhang, Xu Chen, Guangming Ran, Yuanxiao Ma, Adult children's support and self-esteem as mediators in the relationship between attachment and subjective well-being in older adults, Personality and Individual Differences, vol.97, pp. 229-230, 2016.å 